\title{
Could local surgery improve survival in de novo stage IV breast cancer?
}

\author{
Zhenchong Xiong ${ }^{1,2,3 \dagger}$, Guangzheng Deng ${ }^{1,2,3 \dagger}$, Jin Wang ${ }^{1,2,3}$, Xing $\mathrm{Li}^{1,2,3}$, Xinhua Xie ${ }^{1,2,3}$, Zeyu Shuang ${ }^{1,2,3}$ \\ and Xi Wang ${ }^{1,2,3^{*}}$ (D)
}

\begin{abstract}
Background: Resection of the primary tumor is recommended for symptom relief in de novo stage IV breast cancer. We explored whether local surgery could provide a survival benefit in these patients and attempted to characterize the population that could benefit from surgery.
\end{abstract}

Methods: Metastatic Breast cancer patients $(N=313)$ with intact primary tumor between January 2006 and April 2013 were separated into two groups according to whether or not they had undergone surgery. The difference in characteristics between the two groups was analyzed using chi-square test, Fisher's exact test and Mann-Whitney test. Univariable and multivariable Cox regression and stratified survival analysis were used to assess the effect of surgery on survival.

Results: Of the 313 patients, 188 (60.1\%) underwent local surgery. Patients with local surgery had a $47 \%$ reduction in mortality risk vs. those with no surgery (median survival 78 months vs. 37 months; $\mathrm{HR}=0.53 ; 95 \% \mathrm{Cl}, 0.36-0.78$ ) after adjustment for clinical and tumor characteristics. Stratified survival analysis showed that patients with bone metastasis alone (and primary tumor $\leq 5 \mathrm{~cm}$ ), soft tissue metastasis, or $\leq 3$ metastasis sites benefit from surgery.

Conclusion: Surgical resection of the primary tumor can improve survival in selected de novo stage IV breast cancer patients.

Keywords: De novo stage IV, Local surgery, Bone metastasis, Soft tissue metastasis, Primary tumor size

\section{Background}

In 2012, about 1.7 million women were diagnosed with breast cancer worldwide, and it is estimated that $5-10 \%$ of them would have presented with de novo stage IV cancer [1-3]. As the advance of systemic treatments (endocrine therapy, cytotoxic therapy, anti-HER2 therapy, and so on) have greatly improved the control of metastatic diseases, local surgery may become feasible to improve survival combined with systemic therapy. Recent studies have suggested that resection of the primary tumor-a procedure that is usually reserved for palliative treatment-could strengthen local control and improve quality of life and progression-free survival in patients with metastatic breast cancer [4-8]. However, more convincing evidence

\footnotetext{
* Correspondence: wangxi@sysucc.org.cn

'Zhenchong Xiong and Guangzheng Deng contributed equally to this work.

1Department of Breast Oncology, Sun Yat-sen University Cancer Center, 651 Dongfeng Road East, Guangzhou 510060, China

${ }^{2}$ State Key Laboratory of Oncology in Southern China, Guangzhou, China Full list of author information is available at the end of the article
}

to support the use of local surgery in stage IV breast cancer is required.

Several studies have shown that advanced local surgery may improve survival in women with metastatic breast cancer [2, 9-13]. Local resection of the primary tumor remains a positive prognostic factor in metastatic breast cancer even after adjustment for age, tumor burden, site of metastasis, race, type of surgery, margin status, and hormone receptor and HER2 receptor status [12-14]. A meta-analysis that included 28,693 patients with stage IV breast cancer found that patients who undergo surgical resection of the primary tumor have better survival than patients who do not undergo surgery [15]. Another group of researchers has suggested that patients with ER (estrogen receptor)/PR (progesterone receptor)-positive or HER2-amplified disease are most likely to benefit from local surgery [16]. One well-designed clinical trial from Turkey (NCT00557986) has shown that surgery significantly improves overall survival (OS) in patients 
with bone metastasis alone [17]. Although no survival benefit of local surgery was shown in patients with metastatic breast cancer, patients with local surgery were reported to have a better local control in a randomized control trial from India [4].

Due to clinical and biological heterogeneity in breast cancer, the exact cohort of patients who can be expected to benefit from local surgery is unknown. Outcomes in stage IV breast cancer vary with the site of metastasis, and this may provide a basis for identifying patients who may be likely to benefit from local surgery. Recent retrospective and clinical studies have consistently found that metastatic breast cancer patients with only bone metastasis benefit from local surgery $[6,13,18]$. However, it is uncertain whether the entire population of stage IV breast cancer patients with bone metastasis or only a subgroup of them should undergo local surgery. Whether patients with metastasis to other sites could benefit from surgery is also unknown. More studies examining the effects of surgery in different types of metastatic breast cancer patients are required to develop clinical practice guidelines.

The aim of this study was to determine if local surgery can improve OS in de novo metastatic breast cancer and to identify the characteristics of the patients who could be expected to benefit from surgery.

\section{Methods \\ Patients}

This retrospective study included 313 patients diagnosed with breast cancer at Sun Yet-sen University Cancer Center between 2006 and 2013. Patients were classified as stage IV breast cancer based on the seventh edition of the American Joint Committee on Cancer (AJCC) staging manual. Patients were eligible for inclusion if they had 1) pathological diagnosis of breast cancer; 2) metastatic disease at the time of diagnosis of breast cancer or developed metastasis within 3 months of diagnosis; and 3) life expectancy $>6$ months. Patients were excluded if they 1) had incomplete follow-up data or 2) had history of previous cancer or synchronous malignant tumors. Ethical approval for the study was obtained from the institutional review board.

Information about pathological findings, age at diagnosis, type of surgery undergone, systemic therapy regimen, radiotherapy, and menstrual status (menopausal or premenopausal) was recorded. Time of death was recorded by clinic review or telephonic interview. Primary tumor status and metastasis status were regularly recorded by clinical and imageological examinations (mammography, ultrasound, and/or MRI for mammary examination; chest CT scan; positron emission tomography-computed tomography/PET-CT; and bone scan) at intervals of
2-4 months; patients with rapidly progressive disease or new symptoms were checked more frequently.

The enrolled patients were divided into two groups: a surgery group and a no surgery group. We defined four kinds of metastatic disease according to the sites involved: visceral metastasis (lungs, pleura, liver, and so on; yes/no), bone metastases (yes/no), soft tissues metastases (distant lymph nodes, skin, subcutaneous tissues; yes/no), and CNS metastases (brain, cranial nerves, and so on; yes/no). The number of metastatic sites was classified as $\leq 3$ or $>3$. HR status and ki-67 status are determined by Immunohistochemistry (IHC), and HER2 receptor status is determined by both $\mathrm{IHC}$ and fluorescence in situ hybridization (FISH). Tumor tissue containing over 1\% of tumor cell which express estrogen receptor (ER)/ progesterone receptor (PR) is defined as HR positive [19]. HER2 receptor amplification is defined as IHC (3+) or FISH $(+)$ while others are defined as HER2 receptor non-amplification [20]. Ki-67 is assessed by calculating the proportion of tumor cells positively expressing Ki-67 [21]. Luminal A subtype is defined as HR positive, Ki-67 < $14 \%$ and HER2 receptor Non-amplification; Luminal B subtype is defined as HR positive, Ki-67 $\geq 14 \%$ /HER2 receptor amplification; HER2 subtype is defined as HER2 amplification and HR negative; Triple negative subtype is defined as HR negative and HER2 receptor Non-amplification [22]. Molecular subtype of breast cancer was categorized based on HR status, HER2 receptor status, and ki-67 status. OS was defined as the interval between the date of diagnosis and the date of death.

\section{Statistical analysis}

Continuous variables were summarized as mean $( \pm$ standard deviation) or median (and range), and were transformed into dichotomous variables at the median value. Comparisons were performed using the chi-square test or Fisher's exact test for categorical variables and the Mann-Whitney test for continuous variables. The Kaplan-Meier method was used to analyze OS, and the log-rank test was used for comparisons between groups. Cox regression model was used to evaluate the association between clinical and tumor characteristics and OS. Individual covariates which significantly correlated with prognosis $(p<0.05)$ in the univariable model were entered into the multivariable model. Unadjusted and adjusted mortality risks (hazard ratios, with 95\% CIs) were calculated. All $p$ values were 2 -sided, and $p \leq 0.05$ were considered significant.

Patients were pre-stratified as factors: bone metastasis only (primary tumor $\leq 5 \mathrm{~cm}$ vs. primary tumor $>5 \mathrm{~cm}$ ), visceral metastasis only (primary tumor $\leq 5 \mathrm{~cm}$ vs. primary tumor $>5 \mathrm{~cm}$ ), soft tissue metastasis only and number of metastasis site ( $\leq 3$ vs. $>3$ ). Cox proportional hazards model was used to assess the mortality risk (hazard ratio 
Table 1 Characteristics of patients who were diagnosed with de novo stage IV breast cancer

\begin{tabular}{lll}
\hline Variable & $\begin{array}{l}\text { No. Patients } \\
(N=313)\end{array}$ & Percentage \\
\hline
\end{tabular}

Age at diagnosis

$\leq 50$

189

39.6

$>50$

124

60.4

Menopause status

Menses
Menopause
Unknown
Biopsy

Mass resection

Core needle

Fine needle

Unknown

Tumor size

$\leq 5 \mathrm{~cm}$

$>5 \mathrm{~cm}$

Unknown

Lymph node involvement

$N_{0}$

$\mathrm{N}_{1}$

$\mathrm{N}_{2}$

$\mathrm{N}_{3}$

Unknown

Hormone receptor status

$+$

Unknown

HER2 receptor status

Amplified

No-amplified

Not known or equivocal(2+)

Molecular subtype

Luminal A

Luminal B

HER2

Triple negative

Unknown*

Surgery

Yes

No

Type of surgery

Modified radical mastectomy

Lumpectomy

Simple mastectomy

Margin status

Negative
27

193

115

5

188

125

181

3

4

5

61.7

36.7

1.6

8.6

73.2

17.9

56

174

120

19
Table 1 Characteristics of patients who were diagnosed with de novo stage IV breast cancer (Continued)

\begin{tabular}{|c|c|c|}
\hline Variable & $\begin{array}{l}\text { No. Patients } \\
(N=313)\end{array}$ & Percentage \\
\hline Positive & 4 & 2.1 \\
\hline \multicolumn{3}{|l|}{ Endocrine therapy\$ } \\
\hline Yes & 123 & 39.3 \\
\hline No & 190 & 60.7 \\
\hline \multicolumn{3}{|l|}{ Anti-HER2 therapy\$ } \\
\hline Yes & 71 & 22.7 \\
\hline No & 239 & 76.4 \\
\hline Unknown & 3 & 1 \\
\hline \multicolumn{3}{|l|}{ Chemotherapy(first line regimen)\$ } \\
\hline CAF/CEF & 9 & 2.9 \\
\hline Taxane based/taxane +anthracyline & 241 & 77.0 \\
\hline Platinum based & 17 & 5.4 \\
\hline Others & 20 & 6.4 \\
\hline Unknown & 26 & 8.3 \\
\hline \multicolumn{3}{|l|}{ Bisphosphonate } \\
\hline Yes & 92 & 29.4 \\
\hline No & 221 & 70.6 \\
\hline \multicolumn{3}{|l|}{ OFS* } \\
\hline Yes & 58 & 18.5 \\
\hline No & 255 & 81.5 \\
\hline \multicolumn{3}{|l|}{ Radiotherapy } \\
\hline Yes & 99 & 31.6 \\
\hline No & 184 & 58.8 \\
\hline Unknown & 30 & 9.6 \\
\hline \multicolumn{3}{|l|}{ Viscera metastasis } \\
\hline Yes & 167 & 53.4 \\
\hline No & 146 & 46.6 \\
\hline \multicolumn{3}{|l|}{ Bone metastasis } \\
\hline Yes & 171 & 54.6 \\
\hline No & 142 & 45.4 \\
\hline \multicolumn{3}{|l|}{ CNS metastasis* } \\
\hline Yes & 11 & 3.5 \\
\hline No & 302 & 96.5 \\
\hline \multicolumn{3}{|l|}{ Soft tissue metastasis } \\
\hline Yes & 139 & 44.4 \\
\hline No & 174 & 55.6 \\
\hline \multicolumn{3}{|l|}{ No. of metastasis sites } \\
\hline$\leq 3$ & 288 & 92.0 \\
\hline$>3$ & 25 & 8.0 \\
\hline \multicolumn{3}{|l|}{ Overall survival(months) } \\
\hline Median & 62 & - \\
\hline 95\% Confidence interval & $45.79-78.21$ & - \\
\hline
\end{tabular}

Abbreviation: *OFS = ovarian function suppression; CNS = central nervous

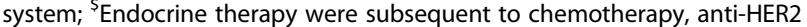
therapy were incorporated into or subsequent to chemotherapy 
Table 2 Comparison of clinical and tumor characteristic between patients who underwent surgery and who did not

\begin{tabular}{|c|c|c|c|}
\hline Variable & $\begin{array}{l}\text { Nonsurgical } \\
(N=125)\end{array}$ & $\begin{array}{l}\text { Surgical } \\
(N=188)\end{array}$ & $p$ value $^{8}$ \\
\hline \multicolumn{4}{|l|}{ Age } \\
\hline$\leq 50$ & $83(43.7 \%)$ & $1107(56.3 \%)$ & 0.092 \\
\hline$>50$ & $42(34.1 \%)$ & $781(65.9 \%)$ & \\
\hline \multicolumn{4}{|l|}{ Menopause status } \\
\hline Menses & $72(36.8 \%)$ & $1122(63.2 \%)$ & 0.144 \\
\hline Menopause & $51(45.2 \%)$ & $663(54.8 \%)$ & \\
\hline \multicolumn{4}{|l|}{ Tumor size } \\
\hline$\leq 5 \mathrm{~cm}$ & $63(36.2 \%)$ & $1111(63.8 \%)$ & 0.018 \\
\hline$>5 \mathrm{~cm}$ & $60(50.0 \%)$ & $560(50.0 \%)$ & \\
\hline \multicolumn{4}{|l|}{ Lymph node involvement } \\
\hline No & $5(17.9 \%)$ & $223(82.1 \%)$ & $0.018 \#$ \\
\hline $\mathrm{N} 1$ & $21(47.7 \%)$ & $23(52.3 \%)$ & \\
\hline N2 & $31(43.7 \%)$ & $340(56.3 \%)$ & \\
\hline N3 & $65(50.4 \%)$ & $664(49.6 \%)$ & \\
\hline \multicolumn{4}{|l|}{ HER-2 receptor status } \\
\hline Amplified & 49(37.1\%) & $783(62.9 \%)$ & $0.657^{£}$ \\
\hline No-amplified & $67(41.6 \%)$ & $994(58.4 \%)$ & \\
\hline Not known or equivocal(2+) & $49(45.0 \%)$ & $511(55.0)$ & \\
\hline \multicolumn{4}{|l|}{ Hormone receptor status } \\
\hline $\mathrm{H}+$ & $81(38.2 \%)$ & $1131(61.8 \%)$ & 0.588 \\
\hline $\mathrm{H}-$ & $39(41.5 \%)$ & $555(58.5 \%)$ & \\
\hline \multicolumn{4}{|l|}{ Molecular subtype } \\
\hline Luminal A & 19(34.5\%) & $36(65.5 \%)$ & 0.194 \\
\hline Luminal B & $54(38.3 \%)$ & $887(61.7 \%)$ & \\
\hline HER2 & 23(41.1\%) & $333(58.9 \%)$ & \\
\hline Triple negative & $12(36.4 \%)$ & $21(63.6 \%)$ & \\
\hline Unknown & $117(60.7 \%)$ & $911(39.3 \%)$ & \\
\hline \multicolumn{4}{|l|}{ Viscera metastasis } \\
\hline Yes & $80(47.9)$ & $887(52.1)$ & 0.002 \\
\hline No & $45(30.8 \%)$ & 9101 (69.2\%) & \\
\hline \multicolumn{4}{|l|}{ Bone metastasis } \\
\hline Yes & 75(43.9\%) & $996(56.1 \%)$ & 0.120 \\
\hline No & $50(35.2 \%)$ & $892(64.8 \%)$ & \\
\hline \multicolumn{4}{|l|}{ CNS metastasis* } \\
\hline Yes & $6(54.5 \%)$ & $5(45.5 \%)$ & 0.314 \\
\hline No & 119(39.4\%) & $1183(60.6 \%)$ & \\
\hline \multicolumn{4}{|l|}{ Soft tissue metastasis } \\
\hline Yes & $58(42.3 \%)$ & $779(57.7 \%)$ & 0.297 \\
\hline No & 67(38.1\%) & $1109(61.9 \%)$ & \\
\hline \multicolumn{4}{|l|}{ No. of metastatic sites } \\
\hline$\leq 3$ & 107(37.2\%) & $1181(62.8 \%)$ & $<0.001$ \\
\hline$>3$ & 18(72\%) & $67(28 \%)$ & \\
\hline
\end{tabular}

Table 2 Comparison of clinical and tumor characteristic between patients who underwent surgery and who did not (Continued)

\begin{tabular}{llll}
\hline Variable & $\begin{array}{l}\text { Nonsurgical } \\
(N=125)\end{array}$ & $\begin{array}{l}\text { Surgical } \\
(N=188)\end{array}$ & $p$ value $^{\text {* }}$ \\
\hline Endocrine therapy & & & \\
Yes & $35(28.5 \%)$ & $888(71.5 \%)$ & 0.001 \\
No & $90(47.4 \%)$ & $9100(52.6 \%)$ & \\
Anti-HER2 therapy & & & \\
Yes & $24(33.8 \%)$ & $447(66.2 \%)$ & $0.055 £$ \\
No & $98(41.0 \%)$ & $1141(59.0 \%)$ & \\
Unknown & $3(100 \%)$ & 0 & \\
OFS* & & & \\
Yes & $12(20.7 \%)$ & $446(79.3 \%)$ & $\mathbf{0 . 0 0 1}$ \\
No & $113(44.3 \%)$ & $1142(55.7 \%)$ & \\
Radiotherapy & & & \\
Yes & $18(18.2 \%)$ & $781(81.8 \%)$ & $<\mathbf{0 . 0 0 1}$ \\
No & $81(44.0 \%)$ & $1103(56.0 \%)$ & \\
Unknown & $26(86.7 \%)$ & $4(13.3 \%)$ &
\end{tabular}

Abbreviation: * OFS = ovarian function suppression; $\mathrm{CNS}=$ central nervous system; ${ }^{5}$ Endocrine therapy were subsequent to chemotherapy; anti-HER2 therapy were incorporated into or subsequent to chemotherapy; ${ }^{8} \times 2$ test, except ${ }^{\mathfrak{f}}$ Fisher' exact test

$P$ values in bold italic are considered statistically significant

and 95\% CI) in each subgroup. The results were displayed in a forest plot.

\section{Results}

Patient characteristics

The study sample comprised 313 metastatic breast cancer patients with intact primary tumors. The median age of the patients was 47 years. Of the 313 patients, 188 (60.1\%) patients received local surgery; $181 / 188$ patients underwent modified radical mastectomy and 184/188 patients had achieved negative margin. The median follow-up duration was 25 months. Median survival was for 62 months. Table 1 shows the clinical and tumor characteristics.

Table 2 shows a comparison of the clinical and tumor characteristics between the surgery group and the no surgery group. Patients undergoing surgery were significantly more likely to have $\leq 3$ metastasis sites $(p<0.001)$, no visceral metastasis $(p=0.002)$, and lower clinical lymph node stage $(p=0.018)$. A significantly higher proportion of patients in the surgery group have tumor size $\leq 5 \mathrm{~cm}$ $(p=0.018)$, received radiotherapy to the chest wall $(p<$ $0.001)$, canonical endocrine therapy $(p=0.001)$, and ovarian function suppression $(p=0.001)$. There was no significant difference with regard to patients' and tumors' characteristics such as age distribution; menstrual status; HER2 status; and HR status; molecular subtypes of tumor; receipt of anti-HER2 therapy; and prevalence of bone, CNS, or soft tissue metastasis (Table 2). 
Table 3 Cox regression predicting mortality risk for Women With Stage IV Breast Cancer (univariable and multivariable)

\begin{tabular}{|c|c|c|c|c|}
\hline Characteristic & Univariable $\mathrm{HR}^{*}(95 \% \mathrm{Cl})$ & $P$ & Multivariable HR $(95 \% \mathrm{Cl})$ & $P$ \\
\hline \multicolumn{5}{|l|}{ Surgery } \\
\hline Yes vs No & $0.56(0.382-0.820)$ & 0.003 & $0.53(0.36-0.78)$ & 0.001 \\
\hline \multicolumn{5}{|l|}{ Viscera metastasis } \\
\hline Yes vs no & $1.73(1.18-2.54)$ & 0.005 & & \\
\hline \multicolumn{5}{|l|}{ Bone metastasis } \\
\hline Yes vs no & $0.91(0.62-1.32)$ & 0.610 & & \\
\hline \multicolumn{5}{|l|}{ CNS metastasis } \\
\hline Yes vs no & $1.40(0.44-4.43)$ & 0.566 & & \\
\hline \multicolumn{5}{|l|}{ Soft tissue metastasis } \\
\hline Yes vs no & $0.99(0.68-1.46)$ & 0.977 & & \\
\hline \multicolumn{5}{|l|}{ Age } \\
\hline$\leq 50$ vs $>50$ & $0.65(0.44-0.95)$ & 0.026 & & \\
\hline \multicolumn{5}{|l|}{ Menopause status } \\
\hline Menopause vs menses & $1.21(0.82-1.77)$ & 0.344 & & \\
\hline \multicolumn{5}{|l|}{ Biopsy } \\
\hline mass resection & $1 \S$ & 0.753 & & \\
\hline core needle & $1.32(0.64-2.73)$ & 0.457 & & \\
\hline fine needle & $1.43(0.18-11.59)$ & 0.736 & & \\
\hline \multicolumn{5}{|l|}{ Histology } \\
\hline ductal & $1 \S$ & 0.824 & & \\
\hline lobular & $0.66(0.16-2.69)$ & 0.563 & & \\
\hline others & $1.11(0.41-3.05)$ & 0.835 & & \\
\hline \multicolumn{5}{|l|}{ Tumor size } \\
\hline$>5 \mathrm{~cm}$ vs $\leq 5 \mathrm{~cm}$ & $1.00(0.67-1.49)$ & 0.981 & & \\
\hline \multicolumn{5}{|l|}{ Lymph node involvement } \\
\hline $\mathrm{N}_{0}$ & $1 \S$ & 0.259 & & \\
\hline$N_{1}$ & $2.48(1.00-6.11)$ & 0.049 & & \\
\hline $\mathrm{N}_{2}$ & $1.95(0.80-4.74)$ & 0.142 & & \\
\hline $\mathrm{N}_{3}$ & $2.14(0.91-5.05)$ & 0.081 & & \\
\hline \multicolumn{5}{|l|}{ HER2 receptor status } \\
\hline Amplified & $1 \S$ & 0.557 & & \\
\hline No-amplified & $0.81(0.55-1.21)$ & 0.304 & & \\
\hline Not known or equivocal $(2+)$ & $0.77(0.31-1.93)$ & 0.574 & & \\
\hline \multicolumn{5}{|l|}{ Hormone receptor status } \\
\hline$+v s-$ & $0.49(0.321-0.7233)$ & $<0.001$ & $0.57(0.36-0.89)$ & 0.013 \\
\hline \multicolumn{5}{|l|}{ No. of metastasis sites } \\
\hline$>3$ vs $\leq 3$ & $1.751(0.881-3.477)$ & 0.11 & & \\
\hline \multicolumn{5}{|l|}{ Endocrine therapy } \\
\hline Yes vs no & $0.45(0.30-0.68)$ & $<0.001$ & $0.55(0.35-0.86)$ & 0.009 \\
\hline \multicolumn{5}{|l|}{ Anti-HER2 therapy } \\
\hline No & $1 \S$ & 0.11 & & \\
\hline Yes & $0.54(0.325-1.008)$ & 0.035 & & \\
\hline Unknown & $0.00(0.00-5.357 E+159)$ & 0.959 & & \\
\hline
\end{tabular}


Table 3 Cox regression predicting mortality risk for Women With Stage IV Breast Cancer (univariable and multivariable) (Continued)

\begin{tabular}{llll}
\hline Characteristic & Univariable $\mathrm{HR}^{*}(95 \% \mathrm{Cl})$ & $\mathrm{P}$ & Multivariable $\mathrm{HR}^{*}(95 \% \mathrm{Cl})$ \\
\hline Radiotherapy & & $\mathbf{0 . 0 2 9}$ & \\
No & $1 \S$ & 0.025 \\
Yes & $0.61(0.40-0.94)$ & 0.357 & \\
Unknown & $1.35(0.71-2.57)$ & & \\
\hline
\end{tabular}

Abbreviation: § Reference; * OFS = ovarian function suppression; CNS = central nervous system; HR = Hazard ratio; ${ }^{\$}$ Endocrine therapy were subsequent to chemotherapy; anti-HER2 therapy were incorporated into or subsequent to chemotherapy

$P$ values in bold italic are considered statistically significant

Univariable and multivariable analysis

Univariable analysis using Cox hazard model showed that patients in the surgery group had lower mortality risk than patients in the no surgery group $(\mathrm{HR}=0.53 ; 95 \% \mathrm{CI}$, $0.36-0.78 ; p=0.001$; Table 3 ). Also, we observed factors: visceral metastasis (yes vs. no $p=0.005$ ), age at diagnosis ( $>50$ vs. $\leq 50 ; p=0.026)$, HR status ( $\mathrm{HR}+$ vs. HR-; $p<0.001$ ), endocrine therapy (yes vs. no; $p<0.001$ ), and radiotherapy (yes vs. no; unknown vs. no; $p=0.029$ ) were significant prognostic factors for OS. Multivariable analysis showed that surgery (yes vs. no; $p=0.001$ ), HR status (HR+ vs. HR-; $p=0.013$ ), and endocrine therapy (yes vs. no; $p=0.009$ ) were independent prognostic factors in de novo stage IV breast cancer.

\section{Overall survival}

Figure 1 shows the Kaplan-Meier survival curves. Patients who underwent surgery had significantly better survival than those who did not accept surgery (median survival: 78 months vs. 37 months; $p=0.002$; Fig. 1a). Surgery did
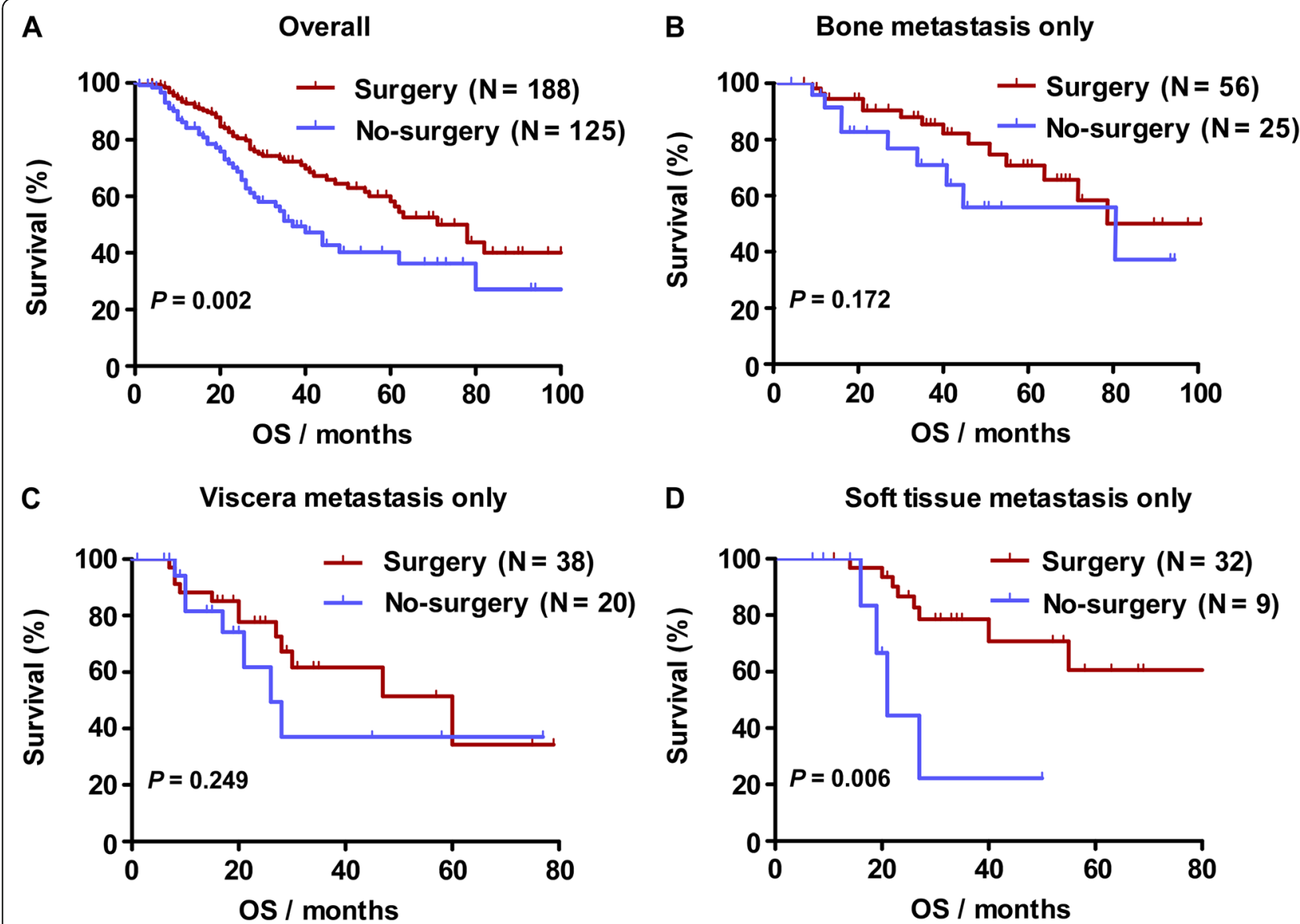

Fig. 1 Kaplan-Meier curves estimate overall survival in: a. de novo stage IV breast cancer (Median survival was 78 months in the surgery group vs 37 months in the no surgery group; log-rank test: $p=0.002$ ); b. bone metastasis only (Median survival was 106 months in the surgery group vs. 80 months in the no surgery group; log-rank test: $p=0.172$ ); c. viscera metastasis only (Median survival was 60 months in the surgery group vs. 26 months in the no surgery group; log-rank test: $p=0.249$ ); $\mathrm{d}$. soft tissue metastasis only (Median survival was 136 months in the surgery group vs. 21 months in the no surgery group; log-rank test: $p=0.006$ ) 
not correlate with better survival in only bone or viscera metastasis patients (median survival: 106 months vs. 80 months; log-rank test: $p=0.172$; median survival: 60 months vs. 26 months; log-rank test: $p=0.249$; Fig. 1b-c). In patients with only soft tissue metastasis, local resection of primary tumor could significantly prolong overall survival (median survival: 136 months vs. 21 months; log-rank test: $p=0.006)$.

\section{Stratified survival analysis}

We used stratified survival analysis to characterize the patient who might be expected to benefit from surgery (Fig. 2). Local surgery significantly reduced mortality risk when the primary tumor was $\leq 5 \mathrm{~cm}$ in size in patients with bone metastasis alone $(\mathrm{HR}=0.27$; $95 \% \mathrm{CI}, 0.08-0.90$; Fig. 2); however, surgery provided no benefit when the primary tumor was $>5 \mathrm{~cm}$ in size $(\mathrm{HR}=1.36$; $95 \% \mathrm{CI}$, 0.34-5.45). Surgery significantly reduced mortality when there was soft tissue metastasis alone $(\mathrm{HR}=0.21 ; 95 \% \mathrm{CI}$, $0.06-0.72)$ or when there were $\leq 3$ metastasis sites $(\mathrm{HR}=$ 0.54; 95\% CI, 0.36-0.81). No survival benefit was observed following surgery in patients who had $>3$ metastasis sites ( $\mathrm{HR}=1.30 ; 95 \% \mathrm{CI}, 0.31-5.37)$, or had visceral metastasis only (irrespective of the tumor size).

\section{Discussion}

This retrospective study was designed to examine how resection of the primary tumor affects survival in patients with de novo stage IV breast cancer and to characterize the population who could be expected to benefit from this surgery. The results showed that resection of the primary tumor could benefit patients with bone metastasis alone (and primary tumor $\leq 5 \mathrm{~cm}$ in size), those with soft tissue metastasis only, and those with $\leq 3$ metastasis sites.

Stage IV breast cancer is considered incurable but treatable [23]. The primary aim of treatment is to delay disease progression and alleviate symptoms. Treatment mostly comprises systemic therapy, including chemotherapy, endocrine therapy, anti-HER2 therapy, and so on; surgery is reserved for tumor bleeding or ulceration [24, 25]. Earlier studies had indicated that the growth of distant metastases could be stimulated by advanced local surgery. Researchers noted that the primary tumor could suppress the growth of distant metastases by secreting angiostatin. Surgical resection reduced angiostatin secretion and also stimulated the release of growth factors, and thus promoted tumor growth [26-28]. However, several retrospective studies have found that local surgery may improve prognosis in breast cancer, renal cell cancer, colorectal cancer, gastric cancer, and melanoma [12, 29-31]. Two experimental study suggested that although surgical resection of the primary tumor may cause transient increase in tumor burden, it substantially reduced overall tumor burden and improved survival by restoring immune responsiveness $[32,33]$. It has been suggested that resection of the primary tumor improves survival by both reducing tumor burden and by enhancing sensitivity to chemotherapy [32]. To evaluate the feasibility of local surgery in metastatic breast cancer, several randomized trials have been launched, while two trials have been completed [14, 34]. In 2015, the first trial on the effect of surgery for de novo stage IV breast cancer in India suggested that local surgery did not significantly improve overall survival [4]. Another completed trial (NCT00557986) in Turkey showed that local surgery did not achieve a survival benefit after 3 years of follow-up, but

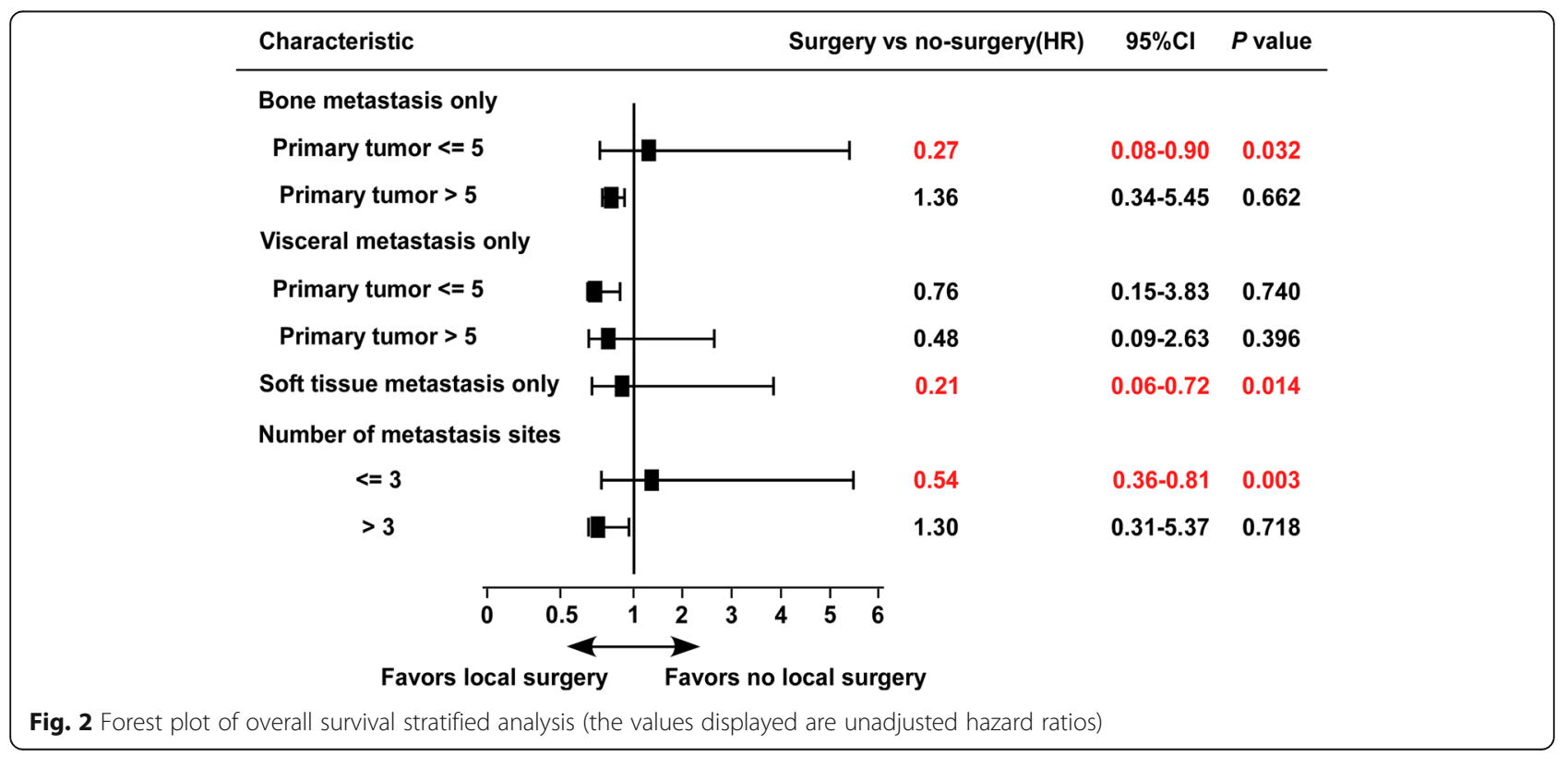


after 5 years follow-up, patients with local surgery achieved a better survival. The effectiveness of local surgery in de novo stage IV breast cancer remains uncertain. Our results, which showed that resection of primary tumor could significantly improve overall survival in de novo stage IV breast cancer, are consistent with the findings of several previous studies $[2,5,9,10,35]$.

The skeleton is the most common site of metastasis in breast cancer patients [36]. Patients with skeletal metastasis are more sensitive to systemic therapy and have relatively better outcomes than patients with metastasis to other sites [37]. Thus, patients with bone metastasis who are responsive to systematic therapy are likely to gain added benefit from local surgery. Previous studies have found that local surgery lowers mortality in breast cancer patients with bone metastasis $[6,13,18]$. Our study also found that patients with only bone metastasis (and with primary tumor $\leq 5 \mathrm{~cm}$ ) benefit from surgery. We also observed a survival benefit following local surgery in patients with only soft tissue metastasis or with $\leq 3$ metastasis sites, and this has not been reported earlier. The underlying mechanism is unclear.

This study had some limitations. This was a singlecenter retrospective study and, inevitably, a selection bias exists. Our findings need to be validated in prospective multicenter studies on larger cohorts.

\section{Conclusions}

In summary, this study demonstrates a survival benefit following local surgery in de novo stage IV breast cancer patients. Stratified survival analysis showed significant survival benefit in patients with bone metastasis only (with primary tumor $\leq 5 \mathrm{~cm}$ ), those with soft tissue metastasis, and those with $\leq 3$ metastasis sites. Thus, in de novo stage IV breast cancer patients who satisfy any of these criteria, it would be reasonable to combine local surgery with systematic therapy.

\section{Abbreviation}

CAF: Cyclophosphamide/doxorubicin/fluorouracil; CEF: Cyclophosphamide/ epirubicin/fluorouracil; CNS: Central nervous system; HR: Hormone receptor; OFS: Ovarian function suppression

\section{Acknowledgements}

We would like to thank the native English speaking scientists of Elixigen Company (Huntington Beach, California) for editing our manuscript.

\section{Avaliability of data and materials}

Raw data was deposited in the Research Data Deposit system of Sun Yat-sen University Cancer (RDDA2018000796) and can be obtained from the corresponding authors on reasonable request.

\section{Funding}

This research did not receive any specific grant from funding agencies in the public, commercial, or not-for-profit sectors.

\section{Authors' contributions}

$X Z C$ and $W X$ designed the overall project: XZC and DGZ analyzed the data and wrote the manuscript; XZC and DGZ collected and analyzed the data;
WJ and SZY performed the research; $L X$ and $X X H$ did the statistical analysis. All the authors $(X Z C, D G Z, W J, L X, X X H, S Z Y, W X)$ have read and approved the final manuscript.

\section{Ethics approval and consent to participate}

Ethical approval was obtained from the respective institutional review boards of the Ethics Committee of Sun Yat-sen University Cancer Center (Approval No: YB2017-04). All patients provided written informed consent to participate in this study.

\section{Consent for publication}

Not applicable

\section{Competing interests}

All the authors declare that they have no conflicts of interest.

\section{Publisher's Note}

Springer Nature remains neutral with regard to jurisdictional claims in published maps and institutional affiliations.

\section{Author details}

${ }^{1}$ Department of Breast Oncology, Sun Yat-sen University Cancer Center, 651 Dongfeng Road East, Guangzhou 510060, China. ${ }^{2}$ State Key Laboratory of Oncology in Southern China, Guangzhou, China. ${ }^{3}$ Collaborative Innovation Center for Cancer Medicine, Guangzhou, China.

Received: 11 January 2018 Accepted: 22 August 2018

Published online: 11 September 2018

\section{References}

1. Siegel R, Naishadham D, Jemal A. Cancer statistics, 2013. CA Cancer J Clin. 2013;63:11-30.

2. Thomas A, Khan SA, Chrischilles EA, Schroeder MC. Initial surgery and survival in stage IV breast Cancer in the United States, 1988-2011. JAMA Surg. 2016;151:424-31

3. Eng LG, Dawood S, Sopik V, Haaland B, Tan PS, Bhoo-Pathy N, Warner E, labal J, Narod SA, Dent R. Ten-year survival in women with primary stage IV breast cancer. Breast Cancer Res Treat. 2016;160:145-52.

4. Badwe R, Hawaldar R, Nair N, Kaushik R, Parmar V, Siddique S, Budrukkar A, Mittra I, Gupta S. Locoregional treatment versus no treatment of the primary tumour in metastatic breast cancer: an open-label randomised controlled trial. The Lancet Oncology. 2015;16:1380-8.

5. Akay CL, Ueno NT, Chisholm GB, Hortobagyi GN, Woodward WA, Alvarez RH, Bedrosian I, Kuerer HM, Hunt KK, Huo L, Babiera GV. Primary tumor resection as a component of multimodality treatment may improve local control and survival in patients with stage IV inflammatory breast cancer. Cancer. 2014;120:1319-28.

6. Shien T, Kinoshita T, Shimizu C, Hojo T, Taira N, Doihara H, Akashi-Tanaka S. Primary tumor resection improves the survival of younger patients with metastatic breast cancer. Oncol Rep. 2009;21:827-32.

7. Hazard HW, Gorla SR, Scholtens D, Kiel K, Gradishar WJ, Khan SA. Surgical resection of the primary tumor, chest wall control, and survival in women with metastatic breast cancer. Cancer. 2008;113:2011-9.

8. Ruiterkamp J, Ernst MF. The role of surgery in metastatic breast cancer. Eur J Cancer. 2011:47(Suppl 3):S6-22

9. Tan Y, Li X, Chen H, Hu Y, Jiang M, Fu J, Yuan Y, Ding K. Hormone receptor status may impact the survival benefit of surgery in stage iv breast cancer: a population-based study. Oncotarget. 2016;7:70991-1000.

10. Rashaan ZM, Bastiaannet E, Portielje JE, van de Water W, van der Velde S, Ernst MF, van de Velde CJ, Liefers GJ. Surgery in metastatic breast cancer: patients with a favorable profile seem to have the most benefit from surgery. Eur J Surg Oncol. 2012;38:52-6.

11. Pathy NB, Verkooijen HM, Taib NA, Hartman M, Yip CH. Impact of breast surgery on survival in women presenting with metastatic breast cancer. $\mathrm{Br}$ J Surg. 2011;98:1566-72

12. Blanchard DK, Shetty PB, Hilsenbeck SG, Elledge RM. Association of Surgery with Improved Survival in stage IV breast Cancer patients. Ann Surg. 2008;247:732-8.

13. Rapiti E, Verkooijen HM, Vlastos G, Fioretta G, Neyroud-Caspar I, Sappino AP, Chappuis PO, Bouchardy C. Complete excision of primary breast tumor improves survival of patients with metastatic breast Cancer at diagnosis. J Clin Oncol. 2006;24:2743-9. 
14. Patrick J, Khan SA. Surgical management of de novo stage IV breast cancer. J Natl Compr Cancer Netw. 2015;13:487-93. quiz 493

15. Harris E, Barry M, Kell MR. Meta-analysis to determine if surgical resection of the primary tumour in the setting of stage IV breast Cancer impacts on survival. Ann Surg Oncol. 2013;20:2828-34.

16. Neuman HB, Morrogh M, Gonen M, Van Zee KJ, Morrow M, King TA. Stage IV breast cancer in the era of targeted therapy. Cancer. 2010;116:1226-33.

17. Soran A, Ozbas S, Kelsey SF, Gulluoglu BM. Randomized trial comparing locoregional resection of primary tumor with no surgery in stage IV breast cancer at the presentation (protocol MF07-01): a study of Turkish Federation of the National Societies for breast diseases. Breast J. 2009;15:399-403.

18. Cady B, Nathan NR, Michaelson JS, Golshan M, Smith BL. Matched pair analyses of stage IV breast cancer with or without resection of primary breast site. Ann Surg Oncol. 2008;15:3384-95.

19. Hammond MEH, Hayes DF, Dowsett M, Allred DC, Hagerty KL, Badve S, Fitzgibbons PL, Francis G, Goldstein NS, Hayes M, et al. American Society of Clinical Oncology/College of American Pathologists Guideline Recommendations for Immunohistochemical testing of estrogen and progesterone receptors in breast Cancer. J Clin Oncol. 2010;28:2784-95.

20. Dressler LG, Berry DA, Broadwater G, Cowan D, Cox K, Griffin S, Miller A, Tse J, Novotny D, Persons DL, et al. Comparison of HER2 status by fluorescence in situ hybridization and immunohistochemistry to predict benefit from dose escalation of adjuvant doxorubicin-based therapy in node-positive breast cancer patients. J Clin Oncol. 2005;23:4287-97.

21. Cheang MC, Chia SK, Voduc D, Gao D, Leung S, Snider J, Watson M, Davies S, Bernard PS, Parker JS, et al. Ki67 index, HER2 status, and prognosis of patients with luminal B breast cancer. J Natl Cancer Inst. 2009;101:736-50.

22. Goldhirsch A, Wood WC, Coates AS, Gelber RD, Thurlimann B, Senn HJ, Panel M. strategies for subtypes--dealing with the diversity of breast cancer: highlights of the St. Gallen international expert consensus on the primary therapy of early breast Cancer 2011. Ann Oncol. 2011;22:1736-47.

23. Xiong Z, Deng G, Huang X, Li X, Xie X, Wang J, Shuang Z, Wang X. Score for the survival probability in metastasis breast Cancer: a nomogram-based risk assessment model. Cancer Res Treat. 2018,

24. Cardoso, F, Costa, A, Senkus, E, Aapro, M, André, F, Barrios, CH, Winer, E 3rd ESO-ESMO International Consensus Guidelines for Advanced Breast Cancer (ABC 3). Ann Oncol. 2017; 28(1):16-33. https://doi.org/10.1093/annonc/ mdw544.

25. Arnedos M, Vicier C, Loi S, Lefebvre C, Michiels S, Bonnefoi H, Andre F. Precision medicine for metastatic breast cancer--limitations and solutions. Nat Rev Clin Oncol. 2015;12:693-704.

26. Folkman J. New perspectives in clinical oncology from angiogenesis research. Eur J Cancer. 1996;32A:2534-9.

27. Fisher ER, Fisher B. Experimental studies of factors influencing the development of hepatic metastases. Xiii. Effect of hepatic trauma in Parabiotic pairs. Cancer Res. 1963;23:896-900.

28. Al-Sahaf O, Wang JH, Browne TJ, Cotter TG, Redmond HP. Surgical injury enhances the expression of genes that mediate breast cancer metastasis to the lung. Ann Surg. 2010;252:1037-43.

29. Flanigan RC, Salmon SE, Blumenstein BA, Bearman SI, Roy V, McGrath PC, Caton JR Jr, Munshi N, Crawford ED. Nephrectomy followed by interferon alfa-2b compared with interferon alfa-2b alone for metastatic renal-cell cancer. N Engl J Med. 2001;345:1655-9.

30. Essner R, Lee JH, Wanek LA, Itakura H, Morton DL. Contemporary surgical treatment of advanced-stage melanoma. Arch Surg. 2004;139:961-6. discussion 966-967

31. Rosen SA, Buell JF, Yoshida A, Kazsuba S, Hurst R, Michelassi F, Millis JM, Posner MC. Initial presentation with stage IV colorectal cancer: how aggressive should we be? Arch Surg. 2000;135:530-4. discussion 534-535

32. Rashid OM, Nagahashi M, Ramachandran S, Graham L, Yamada A, Spiegel S, Bear HD, Takabe K. Resection of the primary tumor improves survival in metastatic breast cancer by reducing overall tumor burden. Surgery. 2013;153:771-8

33. Danna EA, Sinha P, Gilbert M, Clements VK, Pulaski BA, Ostrand-Rosenberg S. Surgical removal of primary tumor reverses tumor-induced immunosuppression despite the presence of metastatic disease. Cancer Res. 2004;64:2205-11.

34. Shien T, Nakamura K, Shibata T, Kinoshita T, Aogi K, Fujisawa T, Masuda N, Inoue $\mathrm{K}$, Fukuda $\mathrm{H}$, Iwata $\mathrm{H}$. A randomized controlled trial comparing primary tumour resection plus systemic therapy with systemic therapy alone in metastatic breast cancer (PRIM-BC): Japan clinical oncology group study JCOG1017. Jpn J Clin Oncol. 2012;42:970-3.
35. Ruiterkamp J, Ernst MF, Van de poll-Franse LV, Bosscha K, Tjan-Heijnen VC, Voogd AC: surgical resection of the primary tumour is associated with improved survival in patients with distant metastatic breast cancer at diagnosis. Eur J Surg Oncol 2009, 35:1146-1151.

36. Xiong Z, Deng G, Huang X, Li X, Xie X, Wang J, Shuang Z, Wang X. Bone metastasis pattern in initial metastatic breast cancer: a population-based study. Cancer Manag Res. 2018;10:287-95.

37. Briasoulis E, Karavasilis V, Kostadima L, Ignatiadis M, Fountzilas G, Pavlidis N. Metastatic breast carcinoma confined to bone: portrait of a clinical entity. Cancer. 2004;101:1524-8.
Ready to submit your research? Choose BMC and benefit from:

- fast, convenient online submission

- thorough peer review by experienced researchers in your field

- rapid publication on acceptance

- support for research data, including large and complex data types

- gold Open Access which fosters wider collaboration and increased citations

- maximum visibility for your research: over $100 \mathrm{M}$ website views per year

At BMC, research is always in progress.

Learn more biomedcentral.com/submissions 